\title{
Giant Cell Tumor of Trapezoid Bone Diagnosis and Treament: A Case Report from Vietnam
}

\author{
Dung Tran Trung*, Lanh Nguyen Sy and Hanh Tran Thi My \\ Department of Pathoanatomy, Hanoi Medical University, VietDuc University Hospital, Vietnam
}

Received: March 31,2018; Published: April 17, 2018

*Corresponding author: Dung Tran Trung, Department of Pathoanatomy, Hanoi Medical University, VietDuc University Hospital, Vietnam, Tel: 84983762005; Email: dungbacsy@dungbacsy.com

\section{Introduction}

Giant cell tumor is a lesion of bone which is relatively common, but giant cell tumor of trapezoid bone is very rare. According to the Literature, there is few case report [1-4] and just 25 patients were reported from 1935 to 2005 [1]. Surgery with bone resection and grafting plays an important role in giant cell tumor. However, late stage giant cell tumor of trapezoid bone usually requires totally bone resection without any bone preservation. The difficulty we can meet when we remove trapezoid bone totally is how we can preserve the function of the hand because this bone is located on 2nd row of carpal bones and connect directly with metacarpal bones. We would like to present one case which was diagnosed in a late-stage and had to be total trapezoid excised and bone plasty successfully and review the literature (Figure 1).

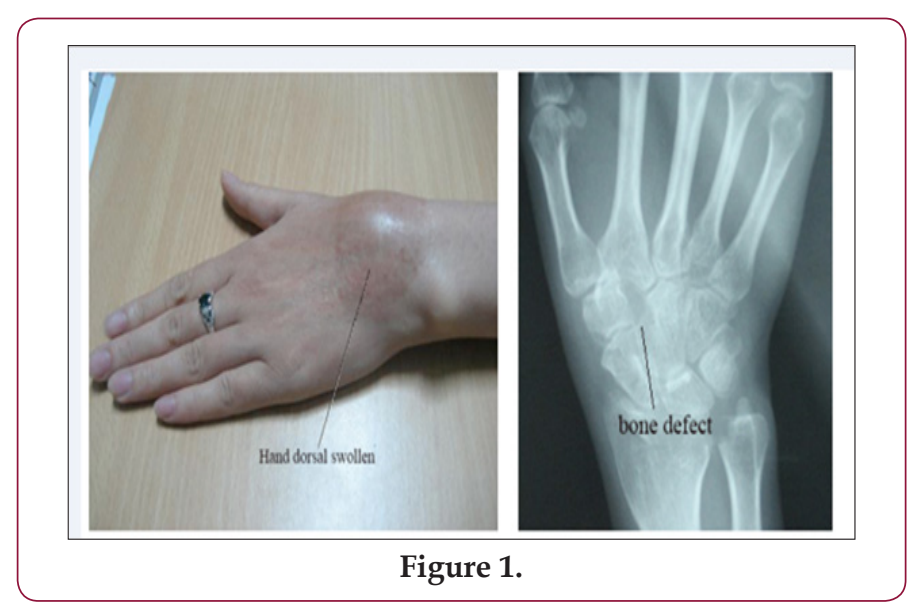

Case Report

A 30-year-old woman admitted to hospital because of left hand dorsal swollen. The onset of disease happened 6 months ago with mild pain on left wrist when movement, increasing gradually by the time. The patient was diagnosed and treated as arthritis in other hospital but the symptoms are not improved and begin swelling the hand dorsal region. On examination, hand dorsal area is swollen but not like abscess condition. X-rays shows mild defect of trapezoid bone. The patient was indicated taking MRI of carpal region. The MRI illustrates total trapezoid bone lesion and spreads to the tissues around. Pre-surgical diagnosis is necrosis inflammation of trapezoid bone. The patient was indicated surgery, got brachial plexus anesthesia and had hand dorsal skin incision above the swelling region. The lesion was seen on total trapezoid bone, spread to the tissues around and to synovial fluid of extensor tendon. There is only periosteum structure of trapezoid bone which is unable to maintain. We decided to remove trapezoid bone totally, synovial fluid of extensor tendon and reconstruct the bone by biological cement. Degree of motion was completely normal when we checked intraoperatively and postoperatively. Clinical features and X-rays routine postoperative are normal. After 9 months of surgery, the patient is not painful and has normal range of motion. The MRI does not reveal tumor recurrence as well as bone structure swollen nearby. The patient was follow-up continuously up to 5 years and there be no any sign and symptom of tumor recurrence clinically and radio graphically.

\section{Discussion}

Giant cell tumor grows commonly at the ends of the body's long bones, rarely at hand bone and more rarely at carpal bones. According to Shigematsu K, there are 29 cases of giant tumor carpal bones were reported all over the world from 1935 to 2005 and only 2 cases related to giant cell tumor of trapezoid bone [1]. Until 2009, Tanrg; et al. reported 1 case giant cell tumor of many regions of carpal bones including trapezoid bone [6]. There is no report about merely giant cell tumor of trapezoid bone. Trapezoid bone injury was reported just 1 case: avascular necrosis of trapezoid bone [5] and 1 case: Osteoma osteoid of the trapezoid bone [7]. All the case was noticed at the late-stage with symptom of painful at carpal region and this is easy to misdiagnose as inflammation of flexor and extensor tendon of the hand [1-4]. Confirming the diagnosis based-on bone defect imaging on X-ray and MRI at latestage. However, on MRI also shows the image of avascular necrosis of trapezoid bone because the image is similar to os lunatum injury 
in Kienbock disease (Figure 2) [5]. The result of pathoanatomy is giant cell tumor (Figure 3). The treatment of giant cell tumor mostly is surgery, removing completely the tumor then autologous bone grafts.
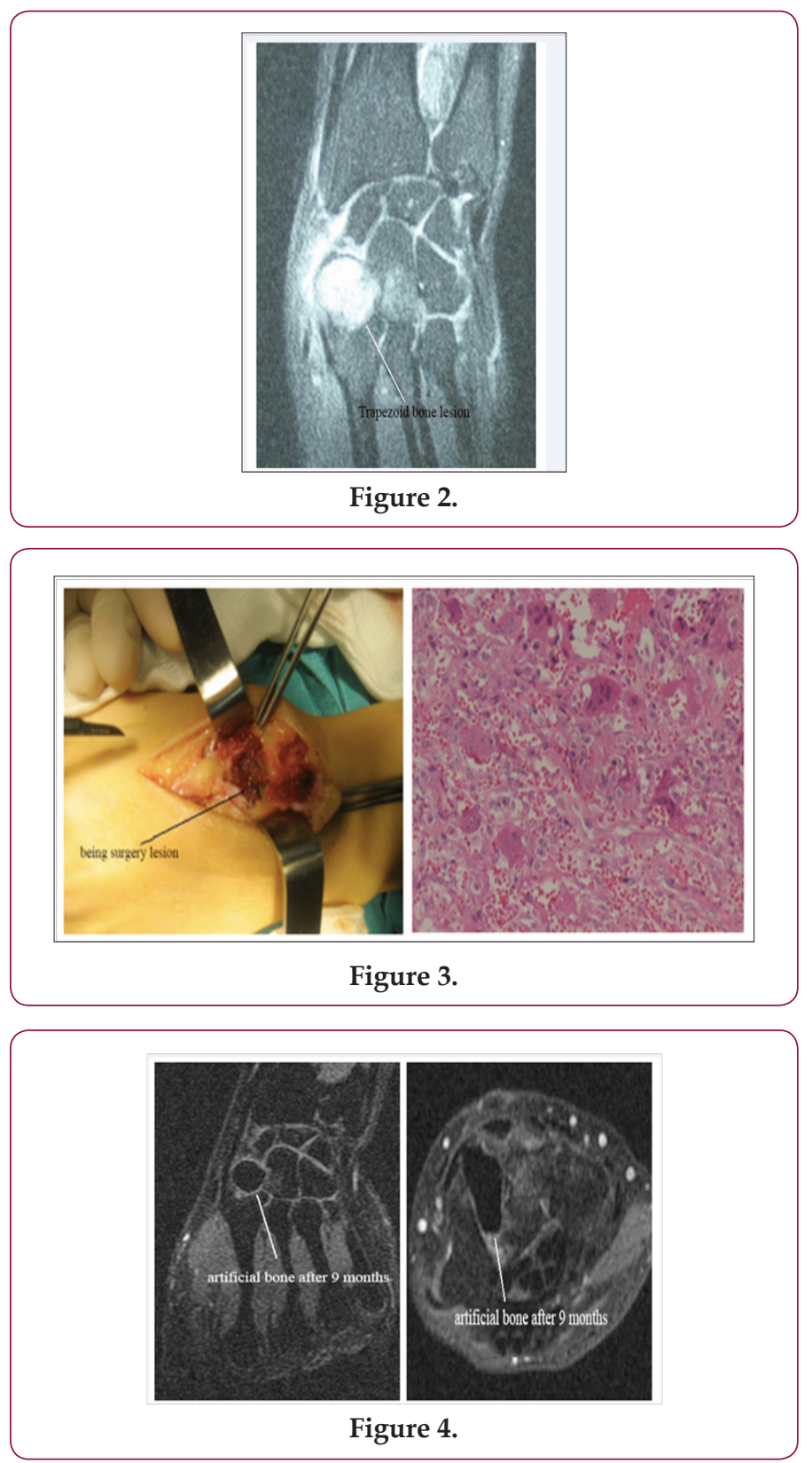

However, carpal bones are very small, so the recurrence rate is significant, up to $24 \%$ no recurrence [1]. One of difficulties is remove total bone but keep maintaining the function of the wrist. Due to recognizing on late-stage, almost cases are taken off total bone and have bone graft or do nothing [1-4,7]. There are other ways used to treat benign diseases of carpal bones such as avascular necrosis of scaphoideum bone (Kienbock disease) and os trapezium bone: bone grafting, palmaris longus tendon or prothese plasty [5]. In our case, we had to remove total the bone, so we could not carry out bone grafts. We reconstructed the trapezoid on by biological cement (Figure 4). There are several risks when using artificial bone: degeneration of bone around due to mechanical impacts, breaking the artificial leads to re-surgery. Follow-up the patient 5 years postoperatively shows that there is no pain in carpal region, the movement range of wrist is completely normal. On MRI, the artificial was not changed, not broken, the bone-around are not swelling (Figure 5). No tumor recurrence and tissue around is detected.

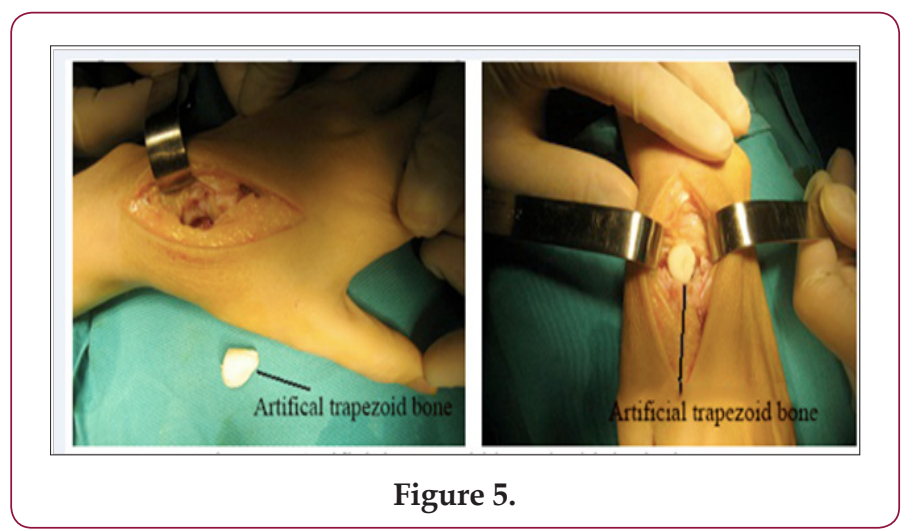

\section{Conclusion}

Giant cell tumor of trapezoid is very rare. Total trapezoid excision and bone-plasty by biological cement show good outcome after 5 years of surgery. There is no tumor recurrence and the function of wrist is normal.

\section{Summary}

Giant cell tumor of trapezoid bone is very rare. We want to present one case which was diagnosed in a late-stage and had to be total trapezoid excision and bone plasty successfully and review the literature.

\section{References}

1. Shigematsu K, Kobata Y, Yajima H, Kawamura K, Maegawa N, et al. (2005) Giant-cell tumors of the carpus. J Hand Surg 31(7): 1214-1219.

2. Weiner SD, Leeson MC (1995) Giant cell tumor of the carpal trapezium. Orthopedics 18(5): 482-484.

3. Vaccari A, Monteleone M, Boselli F, Botticelli A, Mingione A (1990) Giant cell tumor of the hamate bone. Chir Organi Mov 75(1): 77-80.

4. Angelini A, Mavrogenis AF, Ruggieri P (2011) Giant cell tumor of the capitates. Musculoskelet Surg 95(1): 45-48.

5. Sturzenegger M, Mencarelli F (1998) Avascular necrosis of the trapezoid bone. The Journal of Hand Surgery: Journal of the British Society for Surgery of the Hand 23(4): 550-555.

6. Tarng YW, Yang SW, Hsu CJ (2009) Surgical treatment of multifocal giant cell tumor of carpal bones with preservation of wrist function: case report. J Hand Surg Am 34(2): 262-265.

7. Girard J, Becquet E, Limousin M, Chantelot C, Fontaine C (2005) Osteoma osteoid of the trapezoid bone: a case-report and review of the literature. Chir Main 24(1): 35-38. 
(c) (i) This work is licensed under Creative

Submission Link: https://biomedres.us/submit-manuscript.php

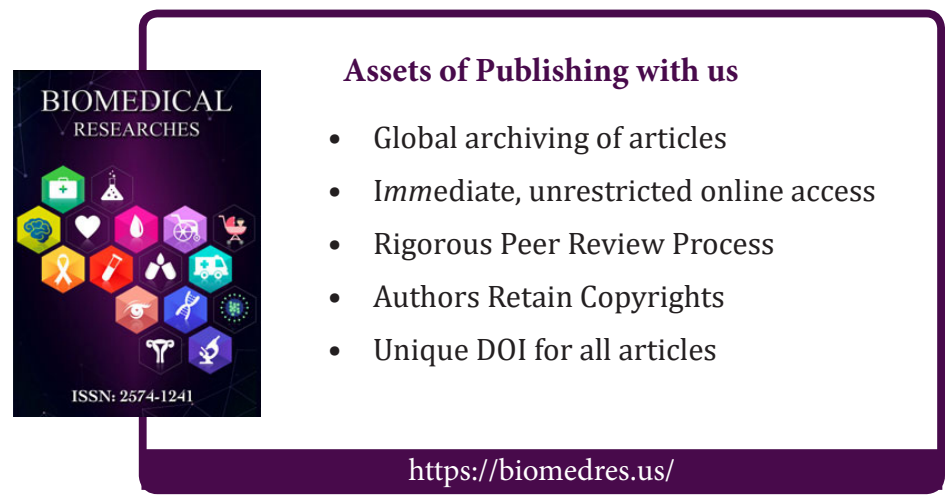

